\title{
Middle Phalanx of Hand
}

National Cancer Institute

\section{Source}

National Cancer Institute. Middle Phalanx of Hand. NCI Thesaurus. Code C12863.

One of four finger bones located between, and articulating with, a proximal phalange and a distal phalange. 